\title{
\begin{tabular}{l|l} 
Mibraries & DSpace@MIT
\end{tabular}
}

MIT Open Access Articles

Digital Data, Platforms and the Usual [Antitrust] Suspects:

Network Effects, Switching Costs, Essential Facility

The MIT Faculty has made this article openly available. Please share how this access benefits you. Your story matters.

As Published: https://doi.org/10.1007/s11151-019-09693-7

Publisher: Springer US

Persistent URL: https://hdl.handle.net/1721.1/131509

Version: Author's final manuscript: final author's manuscript post peer review, without publisher's formatting or copy editing

Terms of use: Creative Commons Attribution-Noncommercial-Share Alike 


\section{Digital Data, Platforms and the Usual [Antitrust] Suspects: Net- work Effects, Switching Costs, Essential Facility}

Cite this article as: Catherine Tucker, Digital Data, Platforms and the Usual [Antitrust] Suspects: Network Effects, Switching Costs, Essential Facility, Review of Industrial Organization https://doi.org/10.1007/s11151-019-09693-7

This Author Accepted Manuscript is a PDF file of an unedited peer-reviewed manuscript that has been accepted for publication but has not been copyedited or corrected. The official version of record that is published in the journal is kept up to date and so may therefore differ from this version.

Terms of use and reuse: academic research for non-commercial purposes, see here for full terms. https://www.springer.com/aam-terms-v1 


\title{
Digital Data, Platforms and the Usual [Antitrust] \\ Suspects: Network Effects, Switching Costs, Essential Facility
}

Catherine Tucker*

February 7, 2019

\begin{abstract}
This paper asks whether the large amounts of digital data that are typically observed on large technology platforms - such as Google, Facebook, Uber and Amazon - typically give rise to structural conditions that would lead to antitrust concerns. In particular, I evaluate whether digital data augments or decreases concerns with regard to network effects and switching costs. I also evaluate whether data should be thought of as an 'essential facility.'
\end{abstract}

Keywords: Platforms, Antitrust, Big Data, Network Effects, Switching Costs

${ }^{*}$ Catherine Tucker is the Sloan Distinguished Professor of Management Science and Research Associate at the NBER. Email: cetucker@mit.edu, Address: MIT Sloan School of Management, 100 Main St, Cambridge, MA 02142. Tel: 6172521499 Fax: (617) 258-7597 
Many new platform business models involve the collection, storing and parsing of data. One of the main charges that have been made against such digital platforms - including Facebook, Amazon, Uber and Google - is that they gain market power based on these databased activities. Recent work by Stucke and Grunes (2016) coined the term 'Data-opoly' to give color to this notion. This paper discusses from an economics perspective whether the notion of a 'Data-opoly' makes sense, using in-depth analysis of whether large swathes of digital data are related to the typical sources of market power.

Specifically, I address three sources of market power that are recognized broadly by economists. The first is network effects. Network effects occur when a good or service increases in usefulness with more users. Firms can derive market power from network effects because they imply increasing returns to firm size. This makes it hard for smaller competitors to attract users. Take, for example, a unified airline reservations system with participation by all the airlines. It is then harder for a smaller airline reservations system with just a handful of airlines participating to compete.

The second source of market power is switching costs, which occur when it is costly for users to switch firms. Switching costs make it harder for competitors to poach customers. For example, potential customers may resist the offer of a cheaper checking account because they anticipate that it will be an enormous hassle to switch the electronic debits and credits associated with that account to a new account. This makes it harder for new banks trying to attract customers to compete.

The third source of market power occurs with an 'essential facility:' - when an input is essential for competitor to compete and the current holder of that facility refuses access to it. A classic example of an essential facility is the railroad bridge across the Mississippi River approaching the St. Louis train station - without being able to cross the bridge, competing rail companies could not serve the St. Louis rail market. ${ }^{1}$

\footnotetext{
${ }^{1}$ United States v. Terminal Railroad Association, 224 U.S. 383 (1912). Economists have questioned
} 
I find little evidence that digital data augments market power due to either network effects or switching costs. Instead, digitization may have weakened these two economic forces, because it frees a user from a particular hardware system. Last, it seems unlikely that data can ever meet the criteria for an essential facility, simply because it is often not very valuable and because, since digital data is non-rival, many sources usually exist. Further, there is a tension between forcing access to data and consumer privacy.

I also offer suggestions as to the right questions or framework that regulators should use when considering whether or not data-driven network effects and switching costs may dampen competition. Similarly, I suggest that regulators should, when evaluating whether data is an essential facility, establish what alternative sources of data are available, and if there are no alternative sources, try to understand what precludes the establishment of such a market.

\section{Is there such a thing as a 'data-driven network effect'?}

\subsection{Network effects are weaker in the digital age than when embedded in hard- ware}

In the 1990s, network effects were viewed as a source of potential market power, especially in technology markets. This argument was central to the antitrust action against Microsoft (Bresnahan, 2001). The argument was that Microsoft used its large user base to encourage software developers and computer hardware markets to focus their efforts on the Windows operating system that relied on the Intel chip. This led to a positive feedback loop that rendered competitive products unattractive and, therefore reinforced both Microsoft's and Intel's market power.

In (Tucker, 2018), I have argued that the switch in digital tools away from hardware has

whether even this example was an essential facility, or was instead a horizontal monopoly (Reiffen and Kleit, 1990) 
weakened the power of network effects for the following reasons:

1. Network effects destabilize market power. While network effects facilitate the rapid growth of platforms, they also accelerate their demise. The demise of MySpace is a dramatic example of this.

2. Network effects can be very localized. For example, when I consider whether to use Dropbox or another file sharing service, I do not care about the total number of users of Dropbox; instead, I care about how many of my handful of collaborators also use it.

3. Users often prefer fewer other users and options in digital contexts. This may be because consumers value curation and a limited set of options, because they find some users off-putting, or because consumers value their privacy.

For these reasons, network effects in our new digital age that are based on data may be weaker and less stable than was previously thought.

\subsection{Economies of scale and scope are not network effects. Neither is it clear that there are increasing returns to scale and scope in data.}

A recent book by two legal scholars Grunes and Stucke (2016) stated that data-driven industries can be 'subject to several network effects:'

1. Traditional network effects, including social networks such as Facebook;

2. Network effects involving the scale of data;

3. Network effects involving the scope of data; and

4. Network effects where the scale and scope of data on one side of the market affect the other side of the market (such as advertising).

In this work, traditional network effects are what economists classically think of as 'direct network effects' or 'same-side' network effects. Direct network effects occur when the value 
of the product or service is larger when more of the same type of user are using the service. Examples include most modern forms of communication technology - from social media, to Slack, to Skype, to even the now-redundant fax machine and telegraph.

The last category of network effect described by Grunes and Stucke (2016) where the "scale and scope of data on one side of the market affect the other side of the market (such as advertising)." is what economists classically think of as 'indirect network effects' or a 'cross-side' network effect. Indirect network effects occur when the value of the product or service is larger for a certain group of users, when more users who are in a different category of users are using the service. A classic example is an operating system: Users benefit as more software developers start developing software; and software developers benefit from having more potential customers.

The middle two categories of network effects described by Grunes and Stucke (2016), are simply known as economies of scale and scope in economics terminology and are considered to be distinct from network effects. An economy of scale occurs when costs increase less than proportionately relative to an increased level of production of a specific product. An economy of scope occurs when there is a proportionate savings in costs relative to an increased level of production of multiple products. Economics distinguishes between economies of scale and scope which operate through cost savings as production increases, and network effects which operate through user benefits enhancement as production increases. Network effects are therefore a reflection of consumers' perception of value, while economies of scale are a reflection of cost-side savings.

There is an empirical question as to whether or not there are economies of scale and scope in big data. There are three useful studies on this point. One is Chiou and Tucker (2017), which is on the specific topic addressed by Stucke and Ezrachi (2016), namely, whether more data enhances search engine results' accuracy through learning by doing. In Chiou and Tucker (2017), we examine what happened to search engine accuracy when the search 
engines changed the length of time that they retained data as a response to a crackdown by the European Commission. We found no effect on search engine accuracy as measured by whether a consumer felt the need to repeat the search. We discuss a potential explanation: That search engines operate a 'long tail' business where many search queries are actually unique. As a result, more data on what consumers did in the past is not useful. Instead, what is useful is smart predictive algorithms that help predict what a user might mean or want by their search. This is another form of learning by doing, which may itself be difficult for entrants to emulate. However, better prediction through learning by doing has obvious benefits for consumers.

A second study explores the question of whether there are economies of scope from digital data. Researchers used Amazon data to explore whether having additional data from multiple products helped improve forecasting (Bajari et al., 2018). They found that though additional data about a single product helped Amazon's ability to forecast demand, there were no gains from more data from other products for the purposes of forecasting.

Neumann et al. (2018) explores accuracy of the data collection and data-profiling industry, and suggests that often advertisers would be better off guessing the gender of a user, rather than using online data profiles built on browsing behavior. The data presented in that study shows that larger data brokers who have access to more data profiles, do not perform any more accurately than data brokers who have data on fewer data profiles.

In general, this evidence suggests that empirically there is little evidence of economies of scale and scope in digital data in the instances where one would expect to find them.

There are two potential explanations for this. The first two studies suggest that personalization and customization undermine the potential for economies of scale and scope in data. If the aim of many digital algorithms is to provide a perfect customized and personalized experience or predictive analysis, then it is not surprising that this is a function not simply of the size of the data that are held, but instead the ability of the firm to take only small 
pieces of relevant data and use the right algorithm on those data.

Second, the third study suggests that the use of data to make useful predictions is not always straightforward. Instead of data mattering for firm performance in data-driven industries, instead what may matter is the quality of the algorithm and the underlying engineering team.

\subsection{When can the strength of network effects be augmented by the presence of digital data?}

At the consumer level, for direct or indirect network effects to be strengthened by digital data, consumers must see benefits to pooling their data with other consumers' data.

One example where this may be true is websites that are devoted to ancestry based on DNA. If my aim is to find potential relatives through commonalities in our genomes, then it makes sense for me to try and to find a genetic-data-sharing platform that has the most people and consequently the most data.

If I am a hospital and I am trying to decide whether to join a health information exchange, then it makes sense that I would be most attracted to the platform that had the most extensive health information data from the largest variety of health providers.

The useful insight from these examples where we would expect network effects to be dependent on data, is that the primary purpose of the platform needs to be premised on the sharing of those data among participants. Though there are technology platforms that focus on this function, there are many for whom that is not a primary function. This suggests, perhaps unsurprisingly, that the relationship between digital data and network effects is contextual and needs to be evaluated on a case-by-case basis. 


\section{How do digital data affect switching costs?}

\subsection{Most digital tools are directed at reducing switching costs.}

Digital data are by their nature virtually costless to transfer between different repositories. As a result, many of the applications and tools that process and use digital data are focused on facilitating this transfer.

Take for example, a mobile operating system. In our mobile world, that would seem to be the direct corollary of the Windows desktop operating system: There are mobile users, handset manufacturers, and app developers. These are clear counterparts to the desktop users, desktop manufacturers, and software developers that interacted over the Windows operating system and the Intel chip in the 1990s.

However it is useful to consider what is different.

First, in the desktop world the costs of writing different software versions for different desktop operating systems were perhaps prohibitively high. By contrast, now if a developer is thinking about developing an app for both Android and iOS, the costs are far lower.

This is because of the development of various software languages that a developer can use to build the baseline functionality of the code before translating it for use in the iOS system or to Java for Android. ${ }^{2}$ Indeed the promise of these platforms is to 'target multiple [mobile] platforms with one code base'. ${ }^{3}$

Second, it is now far easier for users to switch software across two operating systems. This used to be expensive. For example, if someone wanted to switch from Office on Windows to Office on a Mac, they would have had to buy completely new software. They would also have faced problems with data compatibility that would have manifested themselves through documents' formats being corrupted and so on.

\footnotetext{
${ }^{2}$ For an example of such a platform see https://www. codenameone.com/blog/port-native-androidapp-ios-iphone-guide.html

${ }^{3}$ https://cordova.apache.org/
} 
By contrast, if I want to use Microsoft Office today, I can simply subscribe to Office 360. My documents are stored on the cloud and it matters not at all whether I edit them on my Android phone, my Microsoft desktop or my Apple computer. Apple sells the same Microsoft Office subscription as is available for Windows desktop users. ${ }^{4}$

This example highlights two shifts in the software business that facilitate switching: First, the move to store data in the cloud makes porting data between different devices easy. Second, switching has been facilitated by the change in pricing models for many types of software. Rather than buying software upfront, and potentially losing the money when switching, subscriptions allow users more easily to switch between platforms.

Third, it is easy for users to port their data between operating systems. Indeed, Apple provides an app - shown in Figure 1 - to facilitate the move from Android to iOS. Although the switch from iOS is a little less automated on Google, Google provides simple instructions on its websites which are easily followed. ${ }^{5}$

\subsection{When can switching costs be augmented by the presence of digital data?}

Given this analysis, a natural question is when switching costs can be augmented or even driven by the presence of digital data.

Let us imagine an example where, for some reason, there is no digital tool or process for a user to extract the digital data they have stored on a particular platform. The question is then how easy or costly it is for that user to switch platforms. Here, the key question for the user is what the value is of their old data. If the benefit that the user derives from using the platform primarily lies in the fact that the platform stores their historic data for them, then that would potentially give rise to switching costs.

For most consumer-facing applications, it is difficult to see that there would be real switching costs due to the storage of historic data. For example, I don't find the fact that

\footnotetext{
${ }^{4}$ https://www .apple.com/shop/product/HK2Z2LL/A/office-365-personal-1-year-subscription1-license and https://www.microsoft.com/en-us/p/office-365-personal/cfq7ttc0k5bf

${ }^{5}$ https://www. android.com/switch/
} 


\section{It's easy to make the switch to iPhone.}

Everything about iPhone is designed to be easy. That includes switching to one. With just a few steps, you can migrate your content automatically and securely from your Android phone with the Move to IOS app. Or visit an Apple Store - we'll help you move to your new iPhone and get you all set up. Either way, it couldn't be simpler.
$\odot$ Contacts
Message history
( Camera photos and videos
Web bookmarks
( Mail accounts
( Calendars
Free apps

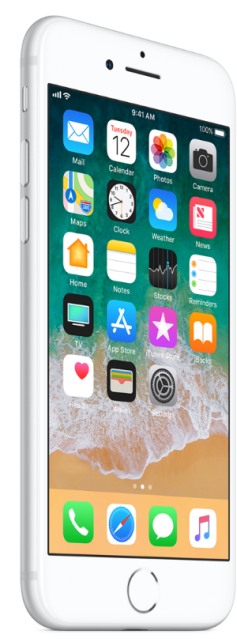

Figure 1: App developed by Apple for users of the Android Operating System 
Amazon has records of all my orders over the past 10 years a particularly compelling reason to not buy from another online platform in the future.

One exception on the consumer side could be health analytics data. It is useful for me to be able to track, for example, my blood pressure over time and monitor changes and factors that seem to shift my readings. In this case, I might be reluctant to give up my health analytics app if it meant losing all those data records.

Another potential exception could be financial data if it were required for tax compliance purposes. For example, I use the program 'Itsdeductible' to store data on my non-monetary donations to charity. Since I need these data for tax compliance purposes, it would be difficult for me to switch midway through the year to another website. ${ }^{6}$

For business facing applications, there may also be similar concerns that are related to regulatory compliance: For example, a firm that is concerned about litigation or audits may find it difficult to leave a platform that keeps records of its earlier actions.

However, there are also many instances even in business-to-business applications where historic data records are not particularly useful. For example, an advertiser is unlikely to keep using the Facebook advertising platform just because it has statistics about the previous years advertising campaign. This example generalizes to any platform where the storage and use of business data is primarily orientated towards short-term tactical decisions. Instead, switching costs seem more likely in instances where businesses store data with regulatory or strategic intent that may actually warrant long-term study and retention.

\section{Are data an essential facility?}

'Essential facility' is a key notion in antitrust law, because denial of access to an essential facility means the monopolist will be immune, at least for some time, to most forms of competition (Pitofsky et al., 2002).

\footnotetext{
${ }^{6}$ Turbotax, which owns Itsdeductible, is only loosely a platform, based on the fact that it may be an intermediary for interactions between me and my tax professional.
} 
There have been claims made that digital data can be an essential facility (Graef, 2016).

From an economics perspective, thinking about standard models of vertical competition, there are three main criteria for whether something is an essential facility. First, is it a valuable input in the production process? Second, are there other means by which rivals can gain access to the input? Last, can a firm actually control who has access to it? Though this is an economist's perspective, it echoes the analysis of Abrahamson (2014) in the context of litigation, who suggests that for data to be an essential facility, the following should hold: 1) The monopolist must control and deny access to the data; 2) competition must fail without access to the data; 3) the plaintiff must lack means to duplicate the data; 4) the monopolist -in principle - must be able to share the data; and 5) the essential facility plaintiff must demonstrate the monopolist's power in the market.

\subsection{Data alone are often not very valuable.}

Much of my research has been focused on the use of data in online advertising. Much of this research has focused on documenting the pitfalls of relying on data rather than understanding consumer behavior in devising online advertising campaigns.

Lambrecht and Tucker (2013) shows that 'retargeting' - a very data-intensive form of online advertising - is not very effective. Retargeted ads track users' browsing behavior, so as to show consumers online display ads for similar products for which consumers previously searched. Though consumers describe these ads as creepy and annoying, great claims have been made for their effectiveness. We show that they are less effective than an ad that uses far less consumer data. This is because such ads are trying to sell products that a customer decided explicitly not to buy, when there is no evidence that the consumer is back in the market for that product.

As discussed above, in Neumann et al. (2018), we highlight other failures of the use of browsing data. In this work, we show that despite collecting extensive browsing data on 
people, many black box algorithms are unable to predict gender correctly more than $50 \%$ of the time. This highlights that browsing data alone is often not predictive about the kind of person who is doing the browsing.

On occasions, where my research has found that data are valuable, what has been striking is the extent to which that value varies across customers. For example, Miller and Tucker (2011) found that data and the healthcare IT that holds and parses these data can be valuable in saving the lives of babies. However, there were many instances these data were not valuable. For educated white mothers whose first language was English and who had no external risk factors, there was little value in the technology. Instead, the value was driven by mothers who were experiencing high-risk births or who came from demographic groups whose needs were poorly addressed through personal interactions with hospital staff.

\subsection{Data are non-rival and widely available}

For an input to be an essential facility, it must be unique and no alternative input is available.

However, this is unlikely to hold for digital data. Digital data are non-rival in their consumption, in that their consumption does not decrease their availability to others. Perhaps more crucially, it is also often non-rival in its production. For example, when I visit the New York Times website multiple firms can learn about that fact from tracking cookies placed there. There could be first-party cookies placed there by the New York Times website, but also cookies placed their by advertising networks, data brokers, and ad metrics firms. ${ }^{7}$

Complementing this non-rivalry is the fact that data has near-zero marginal cost of production and distribution even over long distances. Further large shifts in supply infrastructure have rendered the tools for gathering digital data commonplace. Cloud-based resources such as Amazon, Microsoft, and Rackspace make these tools not dependent on scale ${ }^{8}$ and storage costs for data continue to fall, so that some speculate they may eventually approach

\footnotetext{
${ }^{7}$ There is a small increase in page latency - that is, how quickly it loads - if there are too many cookies, which is why data aggregators can be a helpful tool.

${ }^{8}$ https://aws.amazon.com/s3/pricing/
} 
zero. ${ }^{9}$ This allows ever smaller firms to have access to powerful and inexpensive computing resources. Furthermore, free open source technologies that allow users to analyze large datasets are widely available and accessible (Lambrecht and Tucker, 2017).

These two basic characteristics - combined with the fact that customers constantly leave footprints on the internet - have led to a thriving industry that resells the insights that they gather from digital data.

There are many examples of very big commercially available data sets. The FTC recently investigated 9 major data brokers - Acxiom, Corelogic, Datalogix, eBureau, ID Analytics, Intelius, PeekYou, Rapleaf, and Recorded Future. ${ }^{10}$ The FTC highlighted that 'Data Brokers Store Billions of Data Elements Covering Nearly Every US Consumer. ${ }^{11}$

For example, Acxiom, through its 'Infobase' product, offers "comprehensive consumer data on approximately 250 million U.S. addressable consumers." ${ }^{12}$ Typical data elements that are offered for sale to firms are described in Table 1. The key point of this table is to emphasize that for most elements of consumer behavior that might be part of a data set that is owned by a large technology platform, it is possible for a rival firm to gain that insight through purchasing data from a data broker. The other key insight is that the value of the services that a data broker offers doesn't just depend on the size and scope of the data, but also on the insights and inferences the the broker is able to extract from that data. ${ }^{13}$

These datasets often span multiple data sources to make them even more informative. For example, Comcast licenses its digital TV viewing data to Nielsen to incorporate television viewing data into Nielsen's traditional panel. ${ }^{14}$ For a more general discussion of the

\footnotetext{
${ }^{9}$ http://www.smsmt.com/resources/the-cost-of-the-cloud-the-race-to-zero

${ }^{10}$ https ://qz . com/213900/the-nine-companies-that-know-more-about-you-than-google-orfacebook/

${ }^{11}$ https : //www.ftc.gov/news-events/press-releases/2014/05/ftc-recommends-congressrequire-data-broker-industry-be-more?utm_source=govdelivery

${ }^{12}$ https: //www . acxiom. com/what-we-do/infobase/

${ }^{13}$ Neumann et al. (2018) also suggests that sometimes these insights may not be accurate; it is the scope and size of the data itself that drives value in these markets.

${ }^{14}$ http://www.nielsen.com/us/en/press-room/2017/nielsen-and-comcast-agree-to-
} 
Table 1: Data Elements Commercially Available Through A Data Broker

\begin{tabular}{|c|c|}
\hline Type & Element \\
\hline Demographics & $\begin{array}{l}\text { Age, gender, ethnicity, education, occupa- } \\
\text { tion }\end{array}$ \\
\hline Household Characteristics & Household size, number/ages of children \\
\hline Financial & $\begin{array}{l}\text { Income ranges, net worth, economic stabil- } \\
\text { ity }\end{array}$ \\
\hline Life Events & $\begin{array}{l}\text { Marriage and divorce, birth of children, } \\
\text { home purchase, moves }\end{array}$ \\
\hline Interests & $\begin{array}{l}\text { Sports, leisure activities, family, pets, en- } \\
\text { tertainment }\end{array}$ \\
\hline Buying Activities & Products bought, method of payment \\
\hline Behavior & Community involvement, causes, gaming \\
\hline Major Purchases & $\begin{array}{l}\text { Travel, automotive, real property, technol- } \\
\text { ogy }\end{array}$ \\
\hline
\end{tabular}

expansiveness of online and offline data combinations, see Geronimo (2017).

Therefore, the crucial insight from economics is that there are many firms whose business models are dependent on offering other firms insights via consumer data. Their incentives to provide these data and also success at collecting these data undermine the notion that digital can be a unique 'essential facility' that can be uniquely controlled by a single technology platform.

In general, therefore, there are two questions that a regulator should ask when considering whether data are an essential facility: Is there an alternative source of data that - even if not identical - gives similar insights to the data that a technology platform holds? If there is an alternative data source, is that because that type of data is not generally considered to be very valuable, or because it is indeed impossible to gather and parse such data?

incorporate-set-top-box-viewing-data.html 


\subsection{Privacy protections can give firms the ability to exclude others from the use of particular data}

The last question for an economist is - given that data is non-rival and easy to port - whether a firm can really limit access to it by its rivals.

Generally, this question will be particular to the context and instance of the data that are at issue. For example, YouTube cannot restrict access to data on Shares and Likes of its videos that consumers can see, so as to prevent rivals from accessing these data. There of course can be questions of copyright even regarding publicly posted data. On the other hand, route data for ride-sharing drivers may be something that a ride-sharing platform does not feel the need to share openly and, therefore, the platform controls access to those data.

Given that the question of control over access is context-specific, I focus on the particular tension between allowing access to rivals and protecting consumer privacy. Miller and Tucker (2014) discuss how hospitals often limit the portability of patient data or intentionally 'silo' data while citing privacy concerns as their motivation for doing so. However, as we discuss, this 'siloing' of data under the name of privacy also means that patients are locked into using a specific hospital system or network as they are unable easily to take their x-rays, for example, to another provider.

Campbell et al. (2015) studied the potential anti-competitive effects of privacy regulation in general, in terms of suppressing competition in online advertising markets. The basic idea is that the more strenuous are opt-in requirements, the more likely it is that consumers will opt into sharing their data with just a few firms, rather than being willing to share data with new firms or potential entrants. Though this was a theoretical paper, commentary on the recent GDPR privacy directive in Europe suggest that its insights hold empirically and that GDPR will unintentionally suppress the ability of new start-ups to rival existing large technology platforms. ${ }^{15}$

\footnotetext{
${ }^{15}$ https://www.wsj.com/articles/how-europes-new-privacy-rules-favor-google-and-facebook-
} 


\section{Conclusions}

This paper analyzes whether the large amounts of digital data that are typically observed on large technology platforms - such as Google, Facebook and Amazon - typically give rise to structural conditions that would lead to antitrust concerns.

I conclude that there are many reasons to be optimistic that - rather than reinforcing network effects and switching costs - there are many instances where the process of digitization has weakened them. I also offer a framework to help identify instances where data could give rise to network effects and switching costs. There can be data-driven network effects if the platform's primary purpose is to facilitate data sharing - for example a genomic data-sharing website where people hope to match their genomic data to others' data. There can be data-driven switching costs if companies or individuals cannot easily extract their data, and they have a particular need or utility from historic data rather than more current data.

Last, I consider whether data should be thought of as an essential facility. I suggest that data are unlikely to be an essential facility, because the data are often not that useful and because the data are often ubiquitous. I emphasize that the primary framework for regulators should therefore to be to analyze why there does not exist a market for data that offers similar insights to the data in question. I also note the tension between consumer protection and antitrust in this arena, in that the easiest way for companies actually to foreclose access to data is on the basis of privacy regulation or the stated privacy concerns of sharing it more widely.

1524536324?mod=article_inline 


\section{References}

Abrahamson, Z. (2014). Essential data. Yale Law Journal 124, 867.

Bajari, P., V. Chernozhukov, A. Hortaçsu, and J. Suzuki (2018). The impact of big data on firm performance: An empirical investigation. NBER Working Paper No. 24334.

Bresnahan, T. F. (2001). Network effects and Microsoft. Stanford Institute for Economic Policy Research Discussion Paper No. 00-51.

Campbell, J., A. Goldfarb, and C. Tucker (2015). Privacy regulation and market structure. Journal of Economics 83 Management Strategy $24(1), 47-73$.

Chiou, L. and C. Tucker (2017, September). Search engines and data retention: Implications for privacy and antitrust. National Bureau of Economic Research Working Paper: 23815.

Geronimo, M. (2017). Online browsing: Can, should, and may companies combine online and offline data to learn about you. Hastings Science \&5 Technology Law Journal 9, 211.

Graef, I. (2016). Data as essential facility: competition and innovation on online platforms.

Grunes, A. and M. Stucke (2016). Big data and competition policy. Oxford University Press.

Lambrecht, A. and C. Tucker (2013). When does retargeting work? Information specificity in online advertising. Journal of Marketing Research 50(5), 561-576.

Lambrecht, A. and C. E. Tucker (2017, January). Can big data protect a firm from competition? Competition Policy International.

Miller, A. and C. Tucker (2011). Can healthcare information technology save babies? Journal of Political Economy (2), 289-324. 
Miller, A. and C. Tucker (2014, January). Health information exchange, system size and information silos. Journal of Health Economics 33(2), 28-42.

Neumann, N., C. Tucker, and T. Whitfield (2018). How effective is black-box digital consumer profiling and audience delivery?: Evidence from field studies. Mimeo, MIT.

Pitofsky, R., D. Patterson, and J. Hooks (2002). The essential fecilities doctrine under us antitrust law. Antitrust Law Journal 70, 443.

Reiffen, D. and A. N. Kleit (1990). Terminal railroad revisited: Foreclosure of an essential facility or simple horizontal monopoly? The Journal of Law and Economics 33(2), 419438.

Stucke, M. E. and A. Ezrachi (2016). When competition fails to optimize quality: A look at search engines. Yale Journal of Law and Technology 18, 70.

Stucke, M. E. and A. P. Grunes (2016). Big data and competition policy. Oxford, UK: Oxford University Press.

Tucker, C. (2018). Network effects and market power. Antitrust 32(2). 